\title{
Malignant intracerebral nerve sheath tumor in a patient with Noonan syndrome: illustrative case
}

\author{
*Callum M. Allison, MClinRes, ${ }^{1,2}$ Syed Shumon, MBBS, MRCS, ${ }^{1}$ Abhijit Joshi, MBBS, FRCPath, ${ }^{5}$ Annelies Quaegebeur, MD, PhD, FRCPath, ${ }^{6}$ \\ Georges Sinclair, MRCR, MD, ${ }^{3,4}$ and Surash Surash, MBChB, FRCS(Neurosurg), MD, LLM ${ }^{1}$ \\ Departments of ${ }^{1}$ Neurosurgery and ${ }^{5}$ Pathology, Royal Victoria Infirmary, Newcastle Upon Tyne, United Kingdom; ${ }^{2}$ Newcastle University Medical School, Newcastle Upon Tyne, \\ United Kingdom; ${ }^{3}$ Department of Oncology, James Cook University Hospital, Middlesbrough, United Kingdom; ${ }^{4}$ Department of Neurosurgery, Bezmialem Vakif University \\ Hospital, Istanbul, Turkey; and ${ }^{6}$ Division of Neuropathology, National Hospital for Neurology and Neurosurgery, University College London Hospitals NHS Foundation Trust, \\ London, United Kingdom
}

BACKGROUND Malignant peripheral nerve sheath tumors (MPNSTs) within the neuroaxis are rare, usually arising from peripheral and cranial nerves. Even more scarce are cranial subclassifications of MPNSTs termed "malignant intracerebral nerve sheath tumors" (MINSTs). These tumors are aggressive, with a strong tendency for metastasis. With this presentation, alongside resistance to adjunctive therapy, complete excision is the mainstay of treatment, although it is often insufficient, resulting in a high rate of mortality.

OBSERVATIONS The authors report the case of an adult patient with a history of Noonan syndrome (NS) presenting with slowly progressive rightsided hemiparesis and right-sided focal motor seizures. Despite initial imaging and histology suggesting a left frontal lobe high-grade intrinsic tumor typical of a glioblastoma, subsequent molecular analysis confirmed a diagnosis of MINST. The patient's neurological condition improved after grosstotal resection and adjuvant chemo-radiation; he remains on follow-up.

LESSONS MINSTS are rare neoplasms with a poor prognosis; management options are limited, with surgery being the cornerstone of treatment. Reports on rare tumors such as this will increase awareness of this particular pathology and disclose clinical experience. In this case, the authors were unable to establish a definite cause-and-effect relation between NS and MINST. Nevertheless, it remains the first reported case in the literature.

https://thejns.org/doi/abs/10.3171/CASE21146

KEYWORDS malignant peripheral nerve sheath tumor; malignant intracerebral nerve sheath tumor; malignant schwannoma; frontal lobe; intraparenchymal

Malignant peripheral nerve sheath tumors (MPNSTs) occurring within the neuroaxis are rare, usually arising from peripheral and cranial nerves. Even more unusual are subclassifications evolving from the brain parenchyma, widely known as malignant intracerebral nerve sheath tumors (MINSTs). Because of a propensity for fierce regional infiltration and complex metastatic capability, these tumors are considered aggressive. ${ }^{1}$ With this presentation, and a resistance to adjunctive treatment, gross-total resection (GTR) is the mainstay of management; however, recurrence is often considered inevitable, particularly in cases in which GTR is not achieved. ${ }^{2}$ Therefore, MINSTs are associated with a high rate of mortality and poor overall survival; notwithstanding these outcomes, survival figures differ in the literature, particularly at 1 and 5 years after diagnosis, highlighting the need for a review of the literature. Here, we present a rare case of an MINST in the frontal lobe that was initially suspected to be a high-grade glioma, was initially managed with GTR,

\footnotetext{
ABBREVIATIONS CNS = central nervous system; GFAP = glial fibrillary acidic protein; GTR = gross-total resection; LL = lower limb; MAPK = mitogen-activated protein kinase; MINST = malignant intracerebral nerve sheath tumor; MPNST = malignant peripheral nerve sheath tumor; MRI = magnetic resonance imaging; NF-1 = neurofibromatosis- 1 ; NS = Noonan syndrome; TERT = telomerase reverse transcriptase; UL = upper limb; WHO = World Health Organization. INCLUDE WHEN CITING Published June 28, 2021; DOI: 10.3171/CASE21146. SUBMITTED March 10, 2021. ACCEPTED April 29, 2021.

* G. Sinclair and S. Surash contributed equally to this work.

(C) 2021 The authors, CC BY-NC-ND 4.0 (http://creativecommons.org/licenses/by-nc-nd/4.0/).
} 

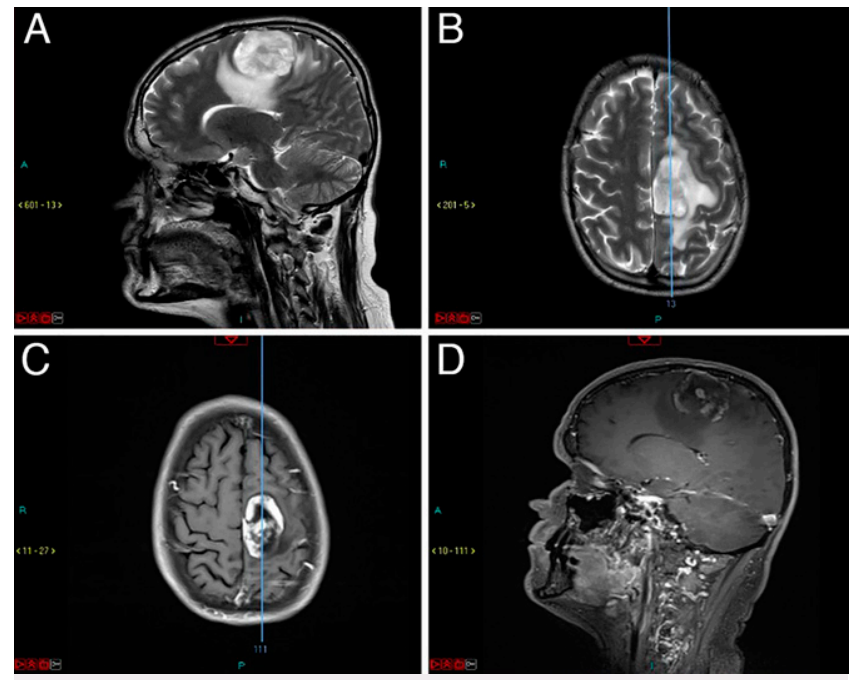

FIG. 1. Preoperative T1- and T2-weighted MRI demonstrating a contrast-enhancing left posterior frontal lesion with necrotic features and surrounding edema. A: Preoperative sagittal T2-weighted MRI. B: Preoperative transverse T2-weighted MRI. C: Postoperative transverse T1-weighted MRI. D: Postoperative sagittal T1-weighted MRI.

and has since completed adjuvant treatment. We have also undertaken a review of the medical literature with the aim to present the latest diagnostic and therapeutic developments on this rare entity.

\section{Illustrative Case}

A 49-year-old, left-handed man with a background of Noonan syndrome (NS) and who had undergone surgery early in childhood for congenital pulmonary stenosis presented to our neurosurgical department with a 7-month history of progressive right-sided hemiparesis and, more acutely, daily focal motor seizures of the right arm and leg.

Neurological examination elicited normal cranial nerve function, including visual fields with no neglect and normal fundoscopy. Motor examination demonstrated normal power and tone in the left upper limb (UL) and lower limb (LL), with a pyramidal catch in the right UL and obvious pyramidal weakness in the right LL (hip flexion $3 / 5$, extension $4 / 5$, knee flexion 4 / 5 , extension $4 / 5$, dorsiflexion $2 / 5$, plantarflexion $4 / 5$ ) with symmetrical, pathologically brisk reflexes. There was reduced sensation down the right arm, leg, and torso to all modalities. His performance status was 2 (according to the World Health Organization [WHO] classification).

Initial magnetic resonance imaging (MRI) in September 2020 demonstrated a heterogeneously enhancing lesion with necrosis, suggestive of a high-grade glioma (Fig. 1). Thus, the patient was listed for a neuronavigated craniotomy for debulking of the lesion after multidisciplinary team review.

Intraoperatively, a linear incision was made and a posterior frontal craniotomy was performed using neuronavigation. An encapsulated tumor was subsequently found and macroscopically excised, achieving GTR. Postoperatively, the patient had a Glasgow Coma Scale score of 15 , with an improving right-sided weakness (UL 2/5, $\mathrm{LL} 3 / 5$ ). Of note, the postoperative MRI and planning MRI for radiotherapy subsequently demonstrated contrast enhancement within the caudal aspect of the surgical bed (Fig. 2), deemed later to be postsurgical inflammatory changes.

Initial histology reports noted an unusual high-grade neoplasm with a predominantly spindle cell appearance. Further immunostaining revealed
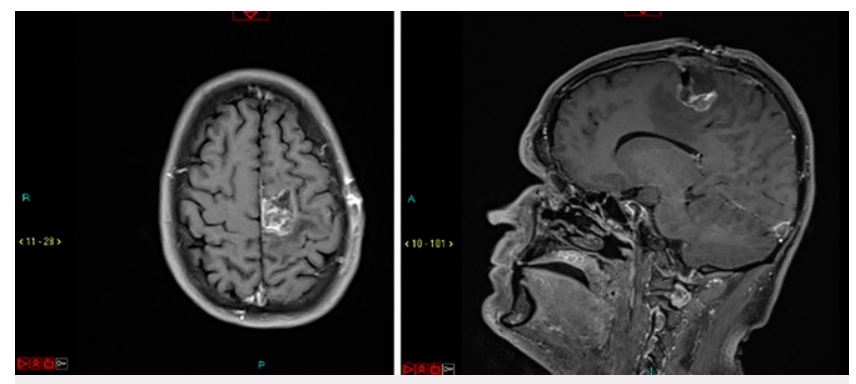

FIG. 2. Postoperative transverse (left) and sagittal (right) T1-weighted MRI demonstrating complete resection of the left paramedian posterior frontal tumor.

a tumor negative for IDH1 (R132H) and BRAF (V600E) mutation with ATRX retention and a Ki-67 labeling index of $20 \%$ to $30 \%$ (complete histomolecular analysis is shown in Table 1). Histological appearances revealed an unusually high-grade, intrinsic central nervous system (CNS) tumor, with a differential diagnosis including gliosarcoma (with a desmoplastic-appearing glial component that also included abnormal ganglion/ neuronal cells) and anaplastic pleomorphic xanthoastrocytoma (Fig. 3). Sanger sequencing further showed the tissue to be IDH1-R132 and IDH2-R172 wild type, with no mutations in the telomerase reverse transcriptase (TERT) promoter or histone H3F3A genes. The DKFZ (German Cancer Research Center, Heidelberg) sarcoma methylation classifier

TABLE 1. Initial immunohistochemistry and molecular pathology analysis results

\begin{tabular}{|c|c|}
\hline $\begin{array}{c}\text { Molecular/Immunohistochemical } \\
\text { Analysis }\end{array}$ & Result \\
\hline IDH (R132H) IHC & Negative \\
\hline IDH1/IDH2 sequencing & No mutation \\
\hline FISH for $1 p / 19 q$ codeletion & Not performed \\
\hline ATRX & $\begin{array}{l}\text { Retained in neoplastic } \\
\text { cell population }\end{array}$ \\
\hline MGMT promoter status & Unmethylated \\
\hline TERT $(228,250)$ & No mutation \\
\hline Histone H3F3A (K27, G34) & No mutation \\
\hline $\begin{array}{l}\text { BRAF (V600E) } \\
\quad(\mathrm{HC} / \text { sequencing) }\end{array}$ & Negative \\
\hline H3K27me3 & Loss of nuclear expression \\
\hline NFP & $\begin{array}{l}\text { Highlights abnormal neuronal } \\
\text { population w/ entrapped axons } \\
\text { in keeping w/ an infiltrative } \\
\text { growth pattern }\end{array}$ \\
\hline GFAP & Patchy positive staining \\
\hline P53 & $\begin{array}{l}\text { A small population of scattered } \\
\text { weakly positive cells }\end{array}$ \\
\hline STAT6 & Negative \\
\hline Ki-67 proliferation & $20 \%-30 \%$ \\
\hline
\end{tabular}

ATRX = ATRX gene; BRAF = B-Raf proto-oncogene; FISH = fluorescent in-situ hybridization; H3K27me3 = histone 3 lysine 27 trimethylation; IDH = isocitrate dehydrogenase; IHC = immunohistochemistry; MGMT = 06-methylguanine DNA methyltransferase; NFP = neurofilament protein; STAT6 = signal transducer and activator of transcription 6 . 

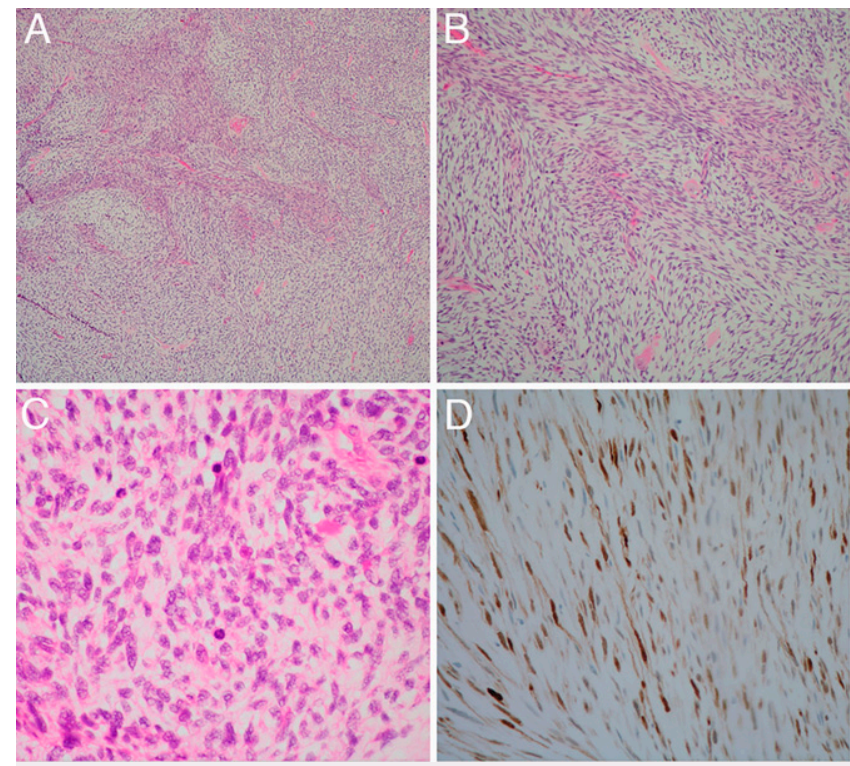

FIG. 3. Light microscopy images showing tumor appearance. A: Original magnification $\times 40$. Hematoxylin and eosin $(H \& E)$ stain demonstrating the alternating compact and loose growth pattern. B: Original magnification $\times 100$. H\&E stain demonstrating a higher-power view of panel A. C: Original magnification $\times 400$. $\mathrm{H} \& \mathrm{E}$ stain showing four mitotic figures (dark structures scattered among the tumor cell nuclei). D: Original magnification $\times 200$. S100 stain demonstrating S100-positive immunohistochemistry labeling in some foci among the tumor cell nuclei and cytoplasm.

categorized this tumor as an MPNST with a high calibrated score. Further support of this diagnosis was provided by the loss of nuclear H3K27me3 expression in the tumor cells. This diagnosis also accounts for the immunohistochemical profile obtained before array analysis.

After bi-institutional multidisciplinary board assessment and review of current data in the medical literature, we offered the patient 6 weeks of adjunctive treatment with concurrent conventional (linear acceleratorbased) radiotherapy (60 Gy in 30 fractions) and temozolomide chemotherapy, to which the patient consented; treatment was completed in February 2021 . He is currently seizure-free and remains cognitively intact; his right-sided hemiparesis has improved, although he still struggles with his LL (LL power 3-4/5, UL power 4/5) while undergoing physiotherapy. His performance status currently is 1 , mainly because of his current neurofunction. His first follow-up MRI (April 2021) showed no evidence of recurrence; the patient is to remain on close surveillance with clinical and MRI follow-ups every 3 months. The interim genetic analysis for neurofibromatosis-1 (NF-1) showed negative results.

\section{Discussion}

\section{Observations}

General Aspects Relevant to This Case

MPNSTs are highly aggressive soft tissue sarcomas. Originally termed "malignant schwannomas," albeit incorrectly because of schwannomas not regularly undergoing malignant transformation, MPNSTs usually arise from the nerves in the limbs or trunk/axillae or form sporadically from existing neurofibromas. ${ }^{3-5}$ Forty percent to $50 \%$ of all MPNSTs occur in the presence of NF-1; however, spontaneous occurrences also have been reported $(50 \%){ }^{6,7}$ Extraaxial sites of occurrence predominantly involve peripheral nerves, specifically in the limbs and trunk, although cranial nerves can also be sites of origin. ${ }^{7,8}$ Spontaneous MPNSTs are scarce, with an incidence of $0.1 /$ 100,000 persons per year. ${ }^{9}$ MPNSTs can be either extra- or intracranial, with the latter type being subclassified into extraaxial and intraparenchymal tumors. Serious consideration was given to this case because intracranial, intraparenchymal MPNSTs are extraordinarily rare, and reports in the international literature remain scarce. Because of the complex anatomo-topographic deployment inherent to their character, these neoplasms are generally known as MINSTs. ${ }^{10}$ Unfortunately, this subclassification is noted to have a penchant for a moderate to poor response to radiation and chemotherapy, with GTR with wide margins considered the cornerstone of management. ${ }^{2,11}$ However, postoperative recurrence and distant metastasis remain likely as a result of the aggressive nature of these tumors; ${ }^{1}$ indeed, the 1 year overall survival rate stands at $33 \% .^{12}$ Therefore, adjunctive radical radiotherapy is often integrated in the portfolio of mainstay therapy.

In the case presented here, there is a background of NS, an autosomal dominant condition with a variable phenotype, in which $50 \%$ of cases are due to a germline "gain of function" mutation of the PTPN11 gene; this particular gene is responsible for encoding the nonreceptor protein tyrosine phosphatase SHP2, positively controlling the RAS function within the RAS-mitogen-activated protein kinase (MAPK) signaling pathway. ${ }^{13,14}$

Considering the nature of the RAS-MAPK pathway and its role in oncogenesis, patients with certain mutations (so-called RASopathies), and thereby NS, are at an increased risk of certain cancers. Somatic mutations of PTPN11 have been reported as being present in $35 \%$ of persons with juvenile myelomonocytic leukemia, alongside other hematological malignancies and solid organ tumors, such as lung and colon cancer and neuroblastoma. ${ }^{15,16}$ Overall, individuals with NS have an estimated cancer risk of $4 \%$ by 20 years old. ${ }^{13,17,18}$

Currently, limited evidence details the relationship between CNS tumors and NS, with most articles providing case reports of pediatric glial tumors. A case report and literature review of these tumors occurring alongside NS by Lodi and colleagues in 2020 demonstrated that most cases occurred in the pediatric population and were dysembryoplastic neuroepithelial tumors. ${ }^{13}$ Adult cases and primary brain tumor reports remain extremely scarce.

The significance of NS preexisting a diagnosis of MINST is unclear in the literature; indeed, should the relationship prove to be causal, our case would provide the first instance of MINST reported in an adult with NS. However, because of the lack of evidence in the medical literature, we tend to remain cautious on this subject.

\section{Diagnosis}

As illustrated by this case, preoperative diagnosis can be difficult, and the lesion's appearance can be indistinguishable from high-grade glioma on imaging. ${ }^{5}$ MR spectroscopy showing a high choline peak without creatine and $\mathrm{N}$-acetyl aspartate resonance has been suggested to differentiate between a glial and nonglial tumor, but awareness and a degree of suspicion are required; ${ }^{19}$ the latter study was not made available for our case because local institutional guidelines are not yet set in that direction. From a histological standpoint, the cellular origin of these neoplasms is still unknown; however, some groups have suggested Schwann cells of perivascular nerves or pluripotent mesenchymal cells as plausible sources. ${ }^{20}$

Important diagnostic markers include the $\mathbf{S 1 0 0}$ protein, useful to demarcate nerve sheath tumors from tertiary soft tissue neoplasms; 
TABLE 2. Summarized cases reported in the literature to date

\begin{tabular}{|c|c|c|c|c|c|c|c|c|c|c|}
\hline $\begin{array}{l}\text { Case } \\
\text { No. }\end{array}$ & Authors \& Yr & $\begin{array}{c}\text { Age } \\
\text { (yrs) at } \\
\text { Diagnosis }\end{array}$ & Gender & Laterality & Location & $\begin{array}{l}\text { Surgical } \\
\text { Procedure }\end{array}$ & $\begin{array}{l}\text { Postop } \\
\text { Therapy }\end{array}$ & $\begin{array}{l}\text { Recurrence } \\
\text { (mos) }\end{array}$ & FU (mos) & $\begin{array}{l}\text { Survival at } \\
\text { Last FU }\end{array}$ \\
\hline 2 & $\begin{array}{l}\text { Le Fèvre et al., } \\
2016^{24}\end{array}$ & 68 & $\mathrm{~F}$ & $\mathrm{Lt}$ & Fronto-temporal & STR & RT & 7 & 15 & Dead \\
\hline 3 & $\begin{array}{l}\text { Le Fèvre et al., } \\
2016^{24}\end{array}$ & 47 & $\mathrm{~F}$ & Rt & Frontal & GTR & RT & $6,10,13$ & 20 & Alive \\
\hline 4 & Smith et al., $2014^{20}$ & 26 & M & - & Bifrontal & STR & - & 1 & 12 & Dead \\
\hline 5 & Lee et al., $2013^{22}$ & 13 & $M$ & $\mathrm{Rt}$ & Frontal & $\begin{array}{l}\text { Resection } \\
\text { (not } \\
\text { specified) }\end{array}$ & RT & $50,54,60$ & 77 & Alive \\
\hline 8 & $\begin{array}{l}\text { van den Munckhof } \\
\text { et al., } 2011^{26}\end{array}$ & 6 & $\mathrm{~F}$ & $\mathrm{Rt}$ & Fronto-parietal & GTR & $\mathrm{RT} \& \mathrm{CT}$ & 15 & 48 & Alive \\
\hline 9 & Ellis et al., $2011^{27}$ & 9 & $\mathrm{~F}$ & Rt & Fronto-temporal & STR & $C T \& R T$ & No & 6 & Alive \\
\hline 10 & Barnard et al., $2011^{28}$ & 75 & $\mathrm{~F}$ & $\mathrm{Lt}$ & Frontal & GTR & RT & No & 12 & Alive \\
\hline 11 & Oztanir et al., $2009^{29}$ & 1 & $\mathrm{~F}$ & $\mathrm{Rt}$ & $\begin{array}{c}\text { Fronto-temporo- } \\
\text { parietal }\end{array}$ & STR & - & - & 1.5 & Dead \\
\hline 12 & $\begin{array}{l}\text { Scheithauer et al., } \\
2009^{8}\end{array}$ & 69 & M & Rt & Frontal & No treatment & - & - & 4 & Dead \\
\hline 17 & Maiuri et al., $2004^{31}$ & 36 & $\mathrm{M}$ & - & Cerebellar vermis & GTR & RT & 6 & 8 & Dead \\
\hline 18 & $\begin{array}{l}\text { Beauchesne et al., } \\
\qquad 2004^{3}\end{array}$ & 35 & M & Rt & Cerebral peduncle & Biopsy & $\mathrm{RT} \& \mathrm{CT}$ & 17 & 29 & Dead \\
\hline 19 & $\begin{array}{l}\text { Bornstein-Quevedo } \\
\text { et al., } 2003^{32}\end{array}$ & 3 & M & $\mathrm{Rt}$ & Parieto-occipital & STR & - & No & 0.33 & Dead \\
\hline 20 & $\begin{array}{l}\text { Takahashi et al., } \\
2000^{33}\end{array}$ & 57 & $M$ & $\mathrm{Rt}$ & Lateral ventricle & GTR & $\mathrm{RT} \& \mathrm{CT}$ & - & 4 & Dead \\
\hline 21 & Tanaka et al., $2000^{34}$ & 4 & $\mathrm{~F}$ & $\mathrm{Rt}$ & Parieto-occipital & GTR & - & No & 19 & Alive \\
\hline 22 & $\begin{array}{c}\text { Sharma et al., } \\
1998^{35}\end{array}$ & 8 & $\mathrm{~F}$ & $\mathrm{Rt}$ & Temporal & GTR & - & No & 17 & Alive \\
\hline 23 & Jung et al., $1995^{36}$ & 40 & $M$ & $\mathrm{Rt}$ & Lateral ventricle & GTR & RT & 8 & 8 & Dead \\
\hline 24 & Singh et al., $1993^{37}$ & 61 & $\mathrm{~F}$ & Rt & Cerebellar & GTR & RT & 10 & 18 & Dead \\
\hline 25 & $\begin{array}{c}\text { Stefanko et al., } \\
1986^{38}\end{array}$ & 15 & $M$ & $\mathrm{Lt}$ & Parieto-occipital & GTR & $\mathrm{RT} \& \mathrm{CT}$ & 5,8 & 9 & Dead \\
\hline 26 & $\begin{array}{l}\text { Bruner \& Armstrong, } \\
1984^{39}\end{array}$ & 18 & $M$ & - & Bifrontal & GTR & - & $24,48,66$ & 66 & Alive \\
\hline
\end{tabular}

$\mathrm{CT}=$ chemotherapy; FU = follow-up; RT = radiotherapy; STR = subtotal resection. 
loss of nuclear H3K27me3 expression, seen in most MPNSTs; ${ }^{7,21}$ negative glial fibrillary acidic protein (GFAP) expression, which helps exclude desmoplastic astrocytoma, gliofibroma, and gliosarcoma; and negative synaptophysin and neurofilament protein, which reliably distinguish MINSTs from desmoplastic ganglioglioma. ${ }^{22}$ Other differential diagnoses include other tumors such as rhabdomyosarcoma, gastrointestinal stromal tumor, and meningioma. ${ }^{20}$

In our case, S100 positivity coexisting with patchy GFAP expression proved challenging and certainly delayed diagnosis. Additionally, as mentioned above, this tumor initially appeared similar to a glioblastoma on imaging. Histologically, this was thought not to be the immediate case because of certain morphological clues such as the appearance of a malignant tumor with a mesenchymal appearance, alongside the aforementioned absent GFAP expression. Gliosarcoma was indeed considered; however, it was deemed unlikely because of the lack of biphasic architecture (only malignant mesenchymal with no high-grade glioma component). A tumor falling within the hemangiopericytoma/solitary fibrous tumor spectrum was also excluded based on STAT6 immunohistochemistry and DNA methylation profiling. The latter also helped to rule out a diagnosis of anaplastic pleomorphic xanthoastrocytoma. Further analysis to differentiate between MINST and other high-grade tumors, such as SOX10 and reticulin staining, could have been conducted; however, local guidelines favor the reliability of H3K27me3 and DNA methylation profiling from a diagnostic perspective. Local capabilities of analyzing Olig2 expression were not available to us at the time of diagnosis. To that end, the histological and immunohistochemical profile of this tumor did not fit with any known high-grade glioma or any other specific entity recognized by the current WHO classification of CNS tumors.

\section{Treatment and Follow-Up}

Surgical management of intracranial MPNSTs is technically complex because of frequent involvement with a cranial nerve. Indeed, Patankar et al. described the challenges associated with resection of an MPNST in the middle cranial fossa and its close involvement with the facial nerve and geniculate ganglion, resulting in a postoperative facial palsy. ${ }^{10}$ Scheithauer and colleagues also reported a similar finding. ${ }^{8}$ In the case discussed within this report, no cranial nerves were involved. Of note, this is not surprising because intraparenchymal MINSTs arise from the brain parenchyma, and as a result cranial nerve involvement remains a less common finding in similar cases. ${ }^{23}$ In terms of adjuvant therapy, radiotherapy remains the most favored approach; Lee et al. found 60 Gy in 30 fractions beneficial in cases of recurrence. ${ }^{22}$ Alternatively, different lines of chemotherapy have been suggested by different authors, including combination vincristine, carboplatin, etoposide, single-agent temozolomide, and ifosfamide-based treatment: ${ }^{3}$ from our institutional experience, combination procarbazine, lomustine, and vincristine or single-agent lomustine may also be options worth considering. However, the outcome is still poor. Overall, we suggest that chemotherapy be given in chemoradiation settings (as in this case) or when radiotherapy is not indicated; also, as shown in Table 2, lifelong follow-up (including MRI) should be considered for those few long-term survivors. In this context, follow-up should be tailored to clinical evolution and survival timeline.

\section{Lessons}

Multiple lessons can be learned from this case, particularly regarding diagnosis and management. (1) There have been few reports of MINSTs in the literature, with only 25 reported since 1984; none of these cases had a background of NS (Table 2). As a result, it is hypothesized that the rarity of malignant intraparenchymal peripheral nerve sheath tumors brings about a lack of evidence on the best management of these lesions, and although there is insufficient evidence to establish a proper cause-and-effect relation between the two entities, it cannot be fully discarded considering NS's oncogenic capability. (2) MINST can mimic glioblastoma clinically, radiologically, and, to some extent, even histopathologically. This possibility highlights the importance of reliable immunohistochemistry and institutional experience with these rare neoplasms. (3) With surgery being the mainstay treatment, postoperative treatment remains surrogate to the clinical evolution of MINSTs. However, the scarce number of patients makes retrospective analytical work and prospective studies hardly feasible; thus, there is a lack of consensus regarding the adequate postoperative and/or adjuvant management of these tumors, although it seems that radiotherapy has a clearer therapeutic role than chemotherapy.

We believe this case to be the 26th reported case of MINST in the available literature; additionally, to our knowledge, this is the first reported case of MINST in an adult patient with a background of NS. However, as pointed out above, the lack of data in the medical literature makes it difficult to discern between a complex causal relation and a mere incidental finding. Finally, we suggest that an international registry focusing on diagnostics, applied treatments, and therapeutic outcome should be considered with the aim of achieving a wider consensus in the management of these rare and complex entities.

\section{Acknowledgments}

We would like to acknowledge Dr. Tuomo Polvikoski, Consultant Neuropathologist at the Royal Victoria Infirmary, for kind assistance with both histological information and images regarding this case.

\section{References}

1. Puffer RC, Graffeo CS, Mallory GW, et al. Brain metastasis from malignant peripheral nerve sheath tumors. World Neurosurg. 2016;92:580.e1-580.e4.

2. Bradford D, Kim A. Current treatment options for malignant peripheral nerve sheath tumors. Curr Treat Options Oncol. 2015;16(3): 328.

3. Beauchesne P, Mosnier JF, Schmitt T, Brunon J. Malignant nerve sheath tumor of the right cerebral peduncle: case report. Neurosurgery. 2004;54(2):500-504.

4. Hirose $T$, Sumitomo M, Kudo $E$, et al. Malignant peripheral nerve sheath tumor (MPNST) showing perineurial cell differentiation. Am J Surg Pathol. 1989;13(7):613-620.

5. Shweikeh F, Drazin D, Bannykh SI. Malignant intracerebral nerve sheath tumors: a case report with review of the literature. Case Rep Surg. 2013;2013:384076.

6. Watson KL, Al Sannaa GA, Kivlin CM, et al. Patterns of recurrence and survival in sporadic, neurofibromatosis type 1-associated, and radiation-associated malignant peripheral nerve sheath tumors. J Neurosurg. 2017;126(1):319-329.

7. Schaefer IM, Fletcher CD, Hornick JL. Loss of H3K27 trimethylation distinguishes malignant peripheral nerve sheath tumors from histologic mimics. Mod Pathol. 2016;29(1):4-13.

8. Scheithauer BW, Erdogan S, Rodriguez FJ, et al. Malignant peripheral nerve sheath tumors of cranial nerves and intracranial contents: a clinicopathologic study of 17 cases. Am J Surg Pathol. 2009; 33(3):325-338.

9. Sedaghat S, Schmitz F, Grözinger M, Sedaghat M. Malignant peripheral nerve sheath tumours in magnetic resonance imaging: primary and recurrent tumour appearance, post-treatment changes, and metastases. Pol J Radiol. 2020;85:e196-e201. 
10. Patankar AP, Sheth JH. Intracranial malignant nerve sheath tumor in the middle cranial fossa: a rare case report with review of literature. Asian J Neurosurg. 2019;14(3):922-926.

11. Wong WW, Hirose T, Scheithauer BW, et al. Malignant peripheral nerve sheath tumor: analysis of treatment outcome. Int J Radiat Oncol Biol Phys. 1998;42(2):351-360.

12. L'heureux-Lebeau B, Saliba I. Updates on the diagnosis and treatment of intracranial nerve malignant peripheral nerve sheath tumors. OncoTargets Ther. 2013;6:459-470.

13. Lodi M, Boccuto L, Carai $A$, et al. Low-grade gliomas in patients with Noonan syndrome: case-based review of the literature. Diagnostics (Basel). 2020;10(8):582.

14. Morales-Rosado JA, Singh $\mathrm{H}$, Olson RJ, et al. Recurrent ganglioneuroma in PTPN11-associated Noonan syndrome: a case report and literature review. Am J Med Genet A. 2021;185(6):1883-1887.

15. Bentires-Alj M, Paez JG, David FS, et al. Activating mutations of the Noonan syndrome-associated SHP2/PTPN11 gene in human solid tumors and adult acute myelogenous leukemia. Cancer Res. 2004;64(24):8816-8820.

16. Loh ML, Vattikuti S, Schubbert S, et al. Mutations in PTPN11 implicate the SHP-2 phosphatase in leukemogenesis. Blood. 2004;103(6): 2325-2331.

17. Jongmans MC, van der Burgt I, Hoogerbrugge PM, et al. Cancer risk in patients with Noonan syndrome carrying a PTPN11 mutation. Eur J Hum Genet. 2011;19(8):870-874.

18. Kratz CP, Rapisuwon S, Reed H, et al. Cancer in Noonan, Costello, cardiofaciocutaneous and LEOPARD syndromes. Am J Med Genet C Semin Med Genet. 2011;157C(2):83-89.

19. Kozić D, Nagulić M, Samardzić M, et al. Intrapontine malignant nerve sheath tumor: MRI and MRS features. Acta Neurol Belg. 2008;108(2):67-71.

20. Smith RE, Kebriaei MA, Gard AP, et al. Intracranial malignant triton tumor in a patient with neurofibromatosis type 1: case report and review of the literature. Brain Tumor Pathol. 2014;31(2):149-154.

21. Prieto-Granada CN, Wiesner T, Messina JL, et al. Loss of H3K27me3 expression is a highly sensitive marker for sporadic and radiation-induced MPNST. Am J Surg Pathol. 2016;40(4):479-489.

22. Lee BS, Kim YG, Kim DH, Lee MS. A long-term survival case of a primary malignant intracerebral nerve sheath tumor. J Korean Neurosurg Soc. 2013;54(3):261-264.

23. Mrowczynski OD, Greiner RJ, Kapadia M, et al. Intracranial malignant peripheral nerve sheath tumor variant: an unusual neurovascular phenotype sarcoma case invading through the petrous bone. Childs Nerv Syst. 2018;34(8):1605-1608.

24. Le Fèvre $C$, Castelli J, Perrin $C$, et al. Malignant intracerebral nerve sheath tumours: two case reports and complete review of the literature cases. Article in French. Cancer Radiother. 2016;20(2):119-132.

25. Gong $L$, Liu XY, Zhang WD, et al. A rare case of malignant triton tumor in the cerebellopontine angle. Diagn Pathol. 2012;7:43.

26. van den Munckhof $P$, Germans MR, Schouten-van Meeteren AY, et al. Recurring intracranial malignant peripheral nerve sheath tumor: case report and systematic review of the literature. Neurosurgery. 2011;68(4):E1152-E1159.

27. Ellis MJ, Cheshier S, Sharma S, et al. Intracerebral malignant peripheral nerve sheath tumor in a child with neurofibromatosis type 1 and middle cerebral artery aneurysm treated with endovascular coil embolization. J Neurosurg Pediatr. 2011;8(4):346-352.
28. Barnard ZR, Agarwalla PK, Jeyaretna DS, et al. Sporadic primary malignant intracerebral nerve sheath tumors: case report and literature review. J Neurooncol. 2011;104(2):605-610.

29. Oztanir N, Emmez H, Aytar MH, et al. Malignant intracerebral giant nerve sheath tumor in a 14-month-old girl with neurofibromatosis type 1: a case report. Childs Nerv Syst. 2009;25(2):253-256.

30. De Cauwer H, Bogers JP, Duwel V, et al. An intracerebral intraparenchymatous triton tumor in a man with neurofibromatosis. $J$ Neurol. 2007;254(8):1009-1011.

31. Maiuri F, Colella G, D'Acunzi G, del Basso de Caro M. Malignant intracerebellar schwannoma. J Neurooncol. 2004;66(1-2):191-195.

32. Bornstein-Quevedo L, Peralta-Olvera F, Marhx-Bracho A, et al. Cerebral malignant nerve sheath tumor, triton tumor variant: case report. Pediatr Dev Pathol. 2003;6(2):168-172.

33. Takahashi $Y$, Sugita $Y$, Abe $T$, et al. Intraventricular malignant triton tumour. Acta Neurochir (Wien). 2000;142(4):473-477.

34. Tanaka M, Shibui S, Nomura K, et al. Malignant intracerebral nerve sheath tumor with intratumoral calcification. Case report. J Neurosurg. 2000;92(2):338-341.

35. Sharma S, Abbott RI, Zagzag D. Malignant intracerebral nerve sheath tumor: a case report and review of the literature. Cancer. 1998;82(3):545-552.

36. Jung JM, Shin HJ, Chi JG, et al. Malignant intraventricular schwannoma. Case report. J Neurosurg. 1995;82(1):121-124.

37. Singh RV, Suys S, Campbell DA, Broome JC. Malignant schwannoma of the cerebellum: case report. Surg Neurol. 1993;39(2):128-132.

38. Stefanko SZ, Vuzevski VD, Maas AI, van Vroonhoven CC. Intracerebral malignant schwannoma. Acta Neuropathol. 1986;71(3-4): 321-325.

39. Bruner JMHJ, Armstrong DL. Immunocytochemistry of recurring intracerebral nerve sheath tumour. J Neuropathol Exp Neurol. 1984;43:296.

\section{Disclosures}

The authors report no conflict of interest concerning the materials or methods used in this study or the findings specified in this paper.

\section{Author Contributions}

Conception and design: Sinclair, Allison, Shumon, Surash. Acquisition of data: Shumon, Allison. Analysis and interpretation of data: Sinclair, Shumon, Allison, Joshi, Quaegebeur. Drafting the article: Sinclair, Allison, Shumon, Quaegebeur. Critically revising the article: Sinclair, Allison, Shumon, Quaegebeur, Surash. Reviewed submitted version of manuscript: all authors. Approved the final version of the manuscript on behalf of all authors: Sinclair. Administrative/technical/material support: Sinclair, Shumon, Joshi. Study supervision: Sinclair, Surash.

\section{Correspondence}

Georges Sinclair: James Cook University Hospital, Middlesbrough, United Kingdom. georges.sinclair@nhs.net. 